\title{
Reduzindo atrasos na avaliaçáo de artigos
}

\section{Bruno Wilhelm Speck}

(1) https://orcid.org/0000-0001-5085-6825

\section{Liliana Sanjurjo ${ }_{(1,3)}$}

(D) https://orcid.org/0000-0003-2334-3658

\section{Martina Ahlert $(1,4)$}

(D) http://orcid.org/0000-0001-5735-5441

\section{Maurício Rombaldi ${ }_{(1,5)}$}

(D) https://orcid.org/0000-0002-0066-7708

\section{Olivia Perez ${ }_{(1,6)}$}

(D) http://orcid.org/0000-0001-9441-7517

(1) Comitê editorial da Revista Brasileira de Ciências Sociais

(2) Professor do Departamento de Ciência Política da FFLCH da Universidade de São Paulo (USP), São Paulo - SP, Brasil.

E-mail: bruno.speck@gmail.com

(3) Pesquisadora (pós-doutorado, PNPD/CAPES) junto ao Programa de Pós-Graduação em Ciências Sociais da Universidade do Estado do Rio de Janeiro (PPCIS/UERJ), Rio de Janeiro - RJ, Brasil.

E-mail: lilisanj@yahoo.com.br

(4) Professora do Departamento de Sociologia e Antropologia e do Programa de Pós-graduação em Ciências Sociais da Universidade Federal do Maranhăo (UFMA), São Luís - MA, Brasil.

E-mail: ahlertmartina@gmail.com.

(5) Professor do Programa de Pós-Graduação em Sociologia da Universidade Federal da Paraíba (UFPB), João Pessoa - PB, Brasil.

E-mail: mauricio.rombaldi@gmail.com

(6) Professora na Universidade Federal do Piauí (UFPI) vinculada aos cursos de bacharelado e mestrado em Ciência Política e ao programa de pósgraduação (mestrado e doutorado) em Políticas Públicas, Teresina - PI, Brasil.

E-mail:889oliviaperez@gmail.com

DOI: $10.1590 / 3610519 / 2020$

A Revista Brasileira de Ciências Sociais (RBCS) é um dos mais tradicionais periódicos acadêmicos das Ciências Sociais no Brasil, cobrindo as áreas da antropologia, ciência política e sociologia. No último ano, ela passou por reformulaçóes importantes. Sendo uma publicação da Associação Nacional de Pós-Graduação e Pesquisa em Ciências Sociais (ANPOCS), a situação da Revista está atrelada ao contexto da Associação. Ainda que tenhamos experimentado um ambiente político-institucional hostil à manutenção de um periódico com padrão

Redigido em 22 de setembro de 2020 de excelência e alto fator de impacto, foi possível abrir novos horizontes à RBCS a partir de uma recomposição da equipe editorial, que padronizou processos, reduziu significativamente o tempo de tramitação de artigos e os custos da publicação.

A atual gestão deu seguimento ao importantíssimo trabalho de colegas antecessores, que elevaram o periódico ao patamar de excelência em que atualmente se encontra. A última gestão da revista realizou reestruturaçóes fundamentais, acompanhando o processo de profissionalização das revistas acadêmicas no país. Entre as principais medidas adotadas, destacase a incorporação da RBCS ao Scielo, a migração da 
versão impressa para a eletrônica e a manutenção do alto padrão dos estudos publicados.

No início de 2019, a atual equipe assumiu o processo editorial tendo como desafio reagir a uma série de restriçóes orçamentárias. Lamentavelmente, a situação financeira da ANPOCS, que a forçou a reduzir o quadro de funcionários, também atingiu a RBCS. Em consequência, parte considerável do trabalho de gestão editorial foi absorvida pela nova equipe, formada por acadêmicos/as que desempenham as atividades de forma voluntária e não remunerada. $\mathrm{O}$ corpo de editores/as e suas atribuiçôes foram ampliados. Além do editor chefe, a revista também passou a ser assumida por editores/as das áreas de Antropologia, Ciência Política e Sociologia que se encarregaram, completamente, das tarefas de tramitaçáo dos textos submetidos. Além disso, contamos com uma editora assistente, remunerada, que se ocupa dos artigos aprovados até sua publicaçáo, e continuamos com serviços profissionalizados de revisão, diagramação e indexação. Durante este ano, os custos da revista foram reduzidos para menos da metade, mas, ainda assim, não garantem a sua sustentabilidade financeira no médio prazo.

\section{Textos submetidos, taxas de aprovaçáo e tempo de tramitaçáo}

A atual equipe editorial se comprometeu com a avaliação dos textos seguindo critérios de qualidade e a sistematização de procedimentos de avaliação da pertinência do artigo (desk review) e avaliação por pelo menos dois/duas pareceristas especialistas no tema no sistema duplo-cego. Nesta segunda fase, os textos são aprovados, rejeitados ou recebem orientações sobre reformulações necessárias. Em caso de necessidade de reformulaçóes, o/a autor/a encaminha uma nova versão do manuscrito reformulado e uma carta resposta aos/às pareceristas que reavaliam o trabalho. A comissão editorial repete o processo até chegar a uma decisão final, sendo raros os casos em que pareceristas precisam emitir uma terceira avaliação. A equipe entende que após três avaliaçóes o texto merece um encaminhamento definitivo, decidindo-se pela sua publicação ou rejeição.
Tendo em vista a redução do tempo de tramitação dos textos, esse procedimento tem sido paulatinamente aperfeiçoado. Entendemos que o compromisso com a celeridade do processo de avaliação é sinônimo de respeito aos/às autores/as, dos/as quais exigimos exclusividade da submissão. As metas com as quais nos comprometemos são: (a) prazo de até 30 dias para a fase de desk review; (b) prazo de até 90 dias para o envio dos primeiros pareceres aos/às autores/as; (c) até 6 meses para a decisão final sobre a publicação ou rejeição do manuscrito; (d) não ultrapassar 9 meses para a publicação de um artigo, considerando-se a data da sua submissão. Obviamente, nem todos os fatores estão sob nosso controle, dado que é necessário respeitar o tempo dos/as pareceristas, um pilar fundamental para a manutenção da qualidade da revista.

No ano de 2020, a equipe atual tem conseguido resultados muito positivos quanto ao tempo de tramitação de artigos. Os gráficos abaixo permitem que seja observado o tempo médio de tramitação dos textos nas suas diferentes fases. Os artigos estão organizados pela data de submissão, agregados por trimestre. Além das informaçôes sobre o tempo médio de tramitação, incluímos também os dados sobre a taxa de rejeição e aprovação nessa fase. Os números de textos tramitados em cada fase estão no pé de cada coluna.

Em termos gerais, os principais resultados que podem ser observados abaixo são:

\section{Desk review (figuras 1 e 2):}

1. A figura 1 informa que no terceiro trimestre de 2018 recebemos 61 artigos, no trimestre seguinte 50 e assim por diante. A cada trimestre o fluxo de artigos submetidos tem variado entre 50 e 95 textos;

2. Ainda na figura 1 , podemos verificar que no primeiro trimestre do período observado 26 dos 61 textos foram encaminhados para pareceristas. O restante foi rejeitado. No trimestre seguinte essa taxa caiu para 12 dos 50 textos submetidos. Em média 31\% dos 
número de textos submetidos

" para parecerista || rejeitados

35

26
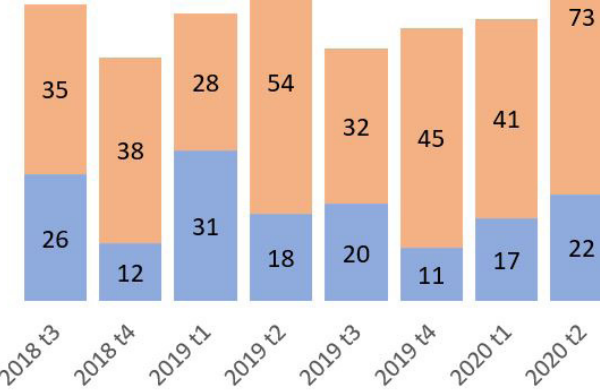

Figura 1: Resultados do desk review (numero de textos)

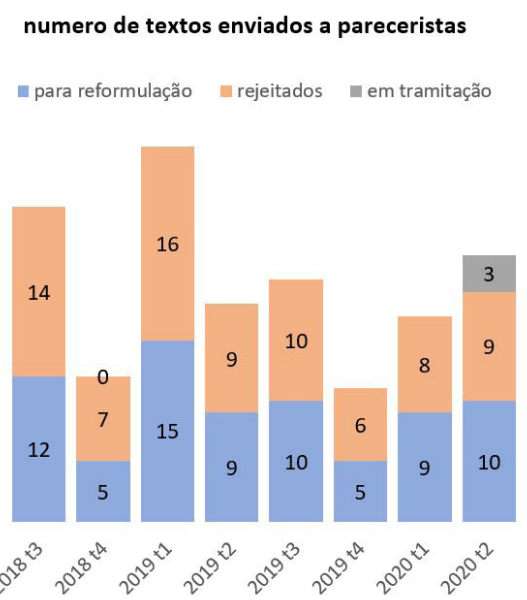

Figura 3: Resultados da primeira avaliação

textos foram aprovados para seguir à próxima etapa, a análise por pareceristas;

3. A figura 2 informa que o tempo médio de tramitação dos textos nessa primeira fase do desk review caiu de 63 dias no primeiro trimestre do período observado para 12 dias no último trimestre observado. dias de tramitação (meta: 30)

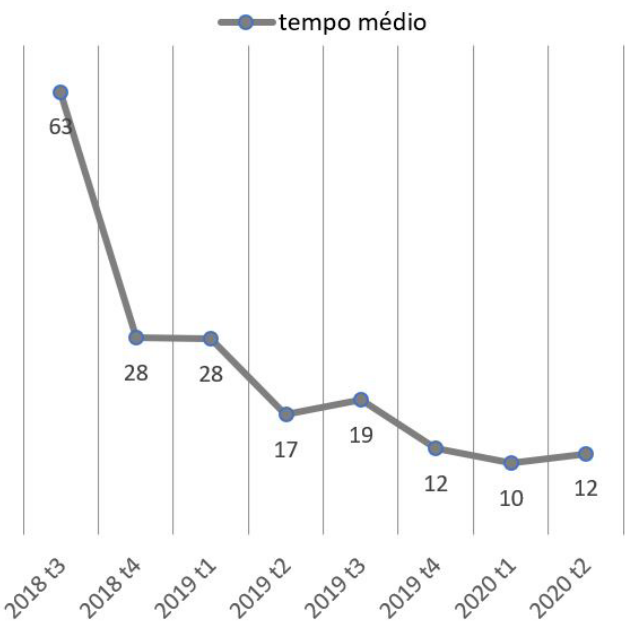

Figura 2: Tempo até desk review

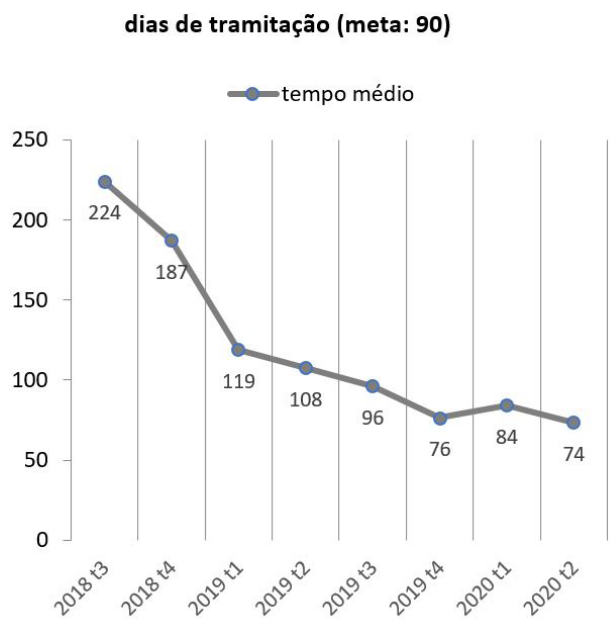

Figura 4: Tempo até primeira avaliação

Primeira avaliação do texto (figuras 3 e 4):

4. A figura 3 informa que entre 11 e 31 textos por trimestre foram encaminhados para pareceristas;

5. No primeiro trimestre do período observado, 14 dos 26 textos foram rejeitados, com base nos pareceres. No período todo, uma média 


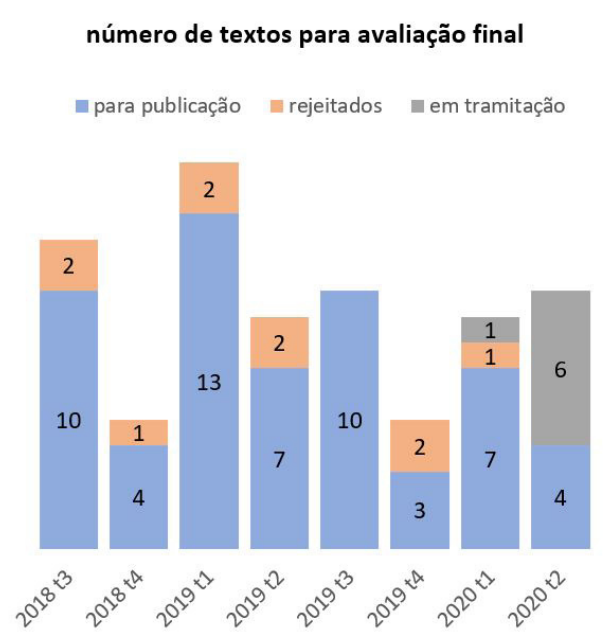

Figura 5: Resultados da decisão final

de 49\% dos trabalhos foram aprovados para seguir tramitando, tipicamente com solicitaçóes de reformulação do texto.

6. A figura 4 informa que conseguimos uma redução no tempo de encaminhamento da primeira avaliação aos/às autores/as: passamos de uma média de 224 dias no terceiro trimestre de 2018, para 73 dias em 2020.

Decisão final sobre os textos submetidos

(figuras 5 e 6):

7. Entre 5 e 15 textos por trimestre seguem para nova avaliação (figura 5);

8. Aproximadamente $85 \%$ dos textos, para os quais os/as pareceristas solicitaram reformulações, foram aprovados após uma ou duas rodadas adicionais;

9. O tempo médio de resposta final sobre os textos que chegaram nessa fase baixou de 421 para 140 dias (figura 6).

\section{Da aprovação até a publicação:}

10. Na última fase, da aprovação final até a publicação, há poucos dados disponíveis,

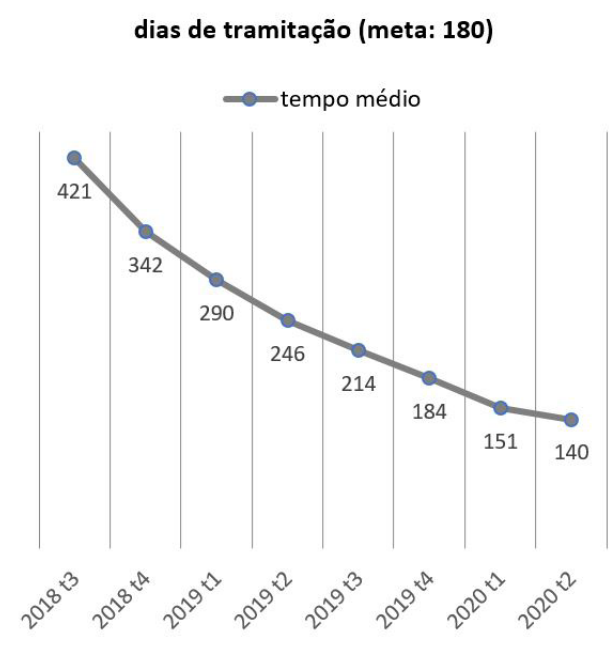

Figura 6: Tempo até decisão final

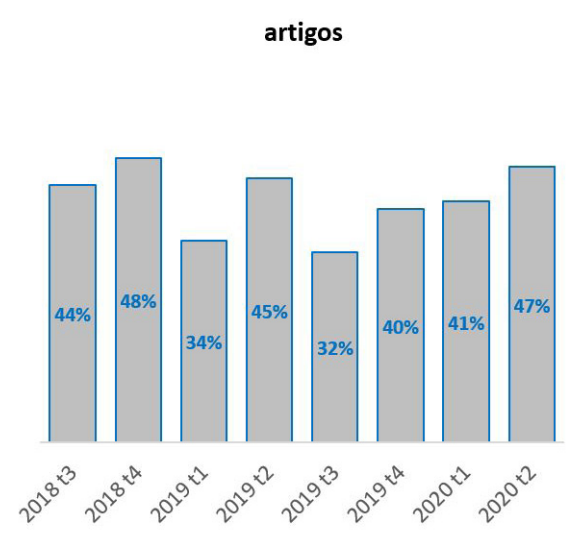

Figura 7: Participação de mulheres em artigos submetidos

embora seja possível perceber que ainda há trabalho a fazer.

\section{A questáo de gênero}

A participação de mulheres nos artigos submetidos à RBCS é de $42 \%$ no período observado. Para chegar a esse número, calculamos a participação feminina na autoria de cada artigo. Em artigos escritos por uma ou mais mulheres, considera-se 
que a participação feminina é equivalente a 100\%. Nos manuscritos com a participação de autores homens, apenas, a participação feminina é de $0 \%$. Um artigo escrito por duas mulheres e um homem tem participação feminina correspondente a $66 \%$. Portanto, a unidade de avaliação é o artigo submetido. Com base nesse levantamento, chegamos a uma taxa média de participação de mulheres de $42 \%$ no período todo. A figura 7 , abaixo, mostra a evolução da participação de mulheres nos artigos submetidos na RBCS, por quadrimestre. Vale lembrar também que, no nosso campo, as mulheres representam quase metade do corpo docente. Na Antropologia 52\% das professoras de Pós-Graduação são mulheres, enquanto na Sociologia elas somam $47 \%$ e na Ciência Política, apenas 34\% (Candido; Feres Júnior; Campos, 2018). A revista reflete aproximadamente essa realidade, mas ainda há espaço para crescer.
Figura 7: Participação média de mulheres nos artigos submetidos

Por último, cabe informar que a ferramenta para gerenciar a tramitaçáo dos textos na revista e produzir os gráficos usados aqui foi disponibilizada no scielo em perspectiva (Speck, 2020).

\section{REFERÊNCIAS}

CANDIDO, Marcia Rangel; FERES JÚNIOR, João; CAMPOS, Luiz Augusto. Boletim OCS: Raça Gênero nas Ciências Sociais: um perfil da Pós-Graduaçáo no Brasil, no. 1, 2018. Disponível em < http://ocs.iesp. uerj.br/boletins/boletim1/ >. Acesso em junho de 2020.

SPECK, B.W. Como reduzir o tempo de tramitação de artigos submetidos: a experiência da Revista Brasileira de Ciências Sociais [online]. SciELO em Perspectiva, 2020 [viewed 22 September 2020]. Available from: https://blog.scielo.org/blog/2020/09/22/ como-reduzir-o-tempo-de-tramitacao-de-artigossubmetidos-a-experiencia-da-revista-brasileira-deciencias-sociais/ 